\title{
A HISTERIA E A PERDA: CONSIDERAÇÕES SOBRE A HISTEROEPILEPSIA DE FIÓDOR M. DOSTOIEVSKI
}

\author{
Edson Manzan Corsi ${ }^{1}$
}

RESUMO: Este trabalho pretende falar sobre o artigo de Sigmund Freud intitulado Dostoievski e o Parricídio, no intuito de defender, mediante o texto freudiano e considerações acerca da obra de Dostoievski, a perspectiva de que a epilepsia do último possuiu etiologia psíquica, e não orgânica. Para tanto, nos utilizamos de textos basilares da psicanálise, mas também da crítica literária.

PALAVRAS-CHAVE: Parricídio; Psicanálise; Epilepsia.

ABSTRACT: this work intends to speak about the article of Sigmund Freud titled Dostoievski and the Parricide, in the goal of defending, by means of the Freudian text and considerations about the work of Dostoievski, the perspective that the epilepsy of the last one possessed psychical etiology, and not organic. In this sense, we used basic texts of psychoanalysis, but also from literary criticism.

KEYWORDS: Parricide; Psychoanalysis; Epilepsy. 

Na segunda metade da década de 1920, foi iniciado o lançamento mercadológico de vários volumes suplementares à edição alemã da obra de Fiódor Dostoievski, contendo esboços inacabados, trabalhos postumamente divulgados e outros tipos de material. Os editores estavam ansiosos por convencer Sigmund Freud a contribuir com um estudo que tratasse do romance Os irmãos Karamassovi e, também, de traços psíquicos do seu autor. Tendo sido Freud contatado por essas pessoas em 1926, o volume ao qual colaborou foi publicado em 1928: trata-se da versão original do citado romance. No volume, o ensaio psicanalítico, cujo nome é Dostoievski e o Parricídio, cumpre o papel de introdução (STRACHEY, 1996). Em seu parágrafo primeiro, a respeito da "rica personalidade" do ficcionista russo, encontram-se apontadas quatro facetas: o artista criador, o neurótico, o moralista e o pecador. A questão do talento artístico é a tratada de forma mais sucinta, Os irmãos Karamassovi é, na leitura freudiana, "o mais grandioso romance jamais escrito; quanto ao episódio do Grande Inquisidor, um dos pontos culminantes da literatura mundial". Mas, "diante do problema do artista criador, a análise, ai de nós, tem de depor suas armas" (FREUD, 1996, p. 183).

O moralista traz dúvidas no que remete ao seu procedimento. O homem moral, se acometido pela tentação de realizar algo leviano em sua perspectiva, busca se livrar da tentação o mais rápido, não se permitindo chegar às vias de fato. Quem "peca" e, depois, devido ao remorso, "erige altos padrões morais, fica exposto à censura de tornar as coisas fáceis demais para si" (FREUD, 1996, p. 183). E não leva em conta a importância prática da conduta moral, da renúncia, para a manutenção da sociedade humana em geral. Ainda, o posicionamento assumido pelo prosador, de submissão à autoridade espiritual e temporal, não é, 
de modo algum, considerado lucrativo. O futuro da civilização, na visão que Freud propõe, não obterá muito que agradecer. A intensidade de seu amor pelos homens, as dimensões de sua inteligência, possivelmente haveriam levado Dostoievski a tomar um caminho apostólico, porém, "parece provável que sua neurose o tenha condenado a esse fracasso" (FREUD, 1996, p. 183).

Acusá-lo de pecador (ou criminoso) seria incoerente pelos seguintes motivos: forte impulso destrutivo e um egoísmo sem limites são traços essenciais na sua constituição. Em Dostoievski, residia grande capacidade de amar e necessidade de amor. Por que se cogitaria denominá-lo criminoso? A sua maneira de narrar isola as personagens violentas de todas as outras, mostrando nele propensões similares. Além disso, certos debates de cunho biográfico indicam que não poderia ser considerado um monstro, nem um santo, entretanto (NUNES, 2004). Freud (1996, p. 184) traz solução plausível

pela compreensão de que o instinto destrutivo muito intenso de Dostoievski, que facilmente poderia tê-lo transformado num criminoso, foi, em sua vida real, dirigido principalmente contra sua própria pessoa,

expressando-se como sentimento de culpa e masoquismo. Não obstante, compareciam muitos traços sádicos em sua personalidade; irritabilidade, intolerância e amor de atormentar - incluindo nisso até as pessoas que amava - explicitados também na maneira pela qual ele trata seus leitores. Assim, no desenvolvimento do texto, procurar-se-á discorrer sobre a temática da tendência autopunitiva do escritor de Crime e Castigo, para daí abordar a hipótese, inserida no ensaio psicanalítico, 
de que - em detrimento do desejo de se punir - aquele veio a sofrer de uma epilepsia histérica (ou histeroepilepsia).

As informações anamnésicas à volta da epilepsia de Dostoievski são precárias, não confiáveis, enquanto "nossa compreensão dos estados patológicos combinados com crises epileptiformes é imperfeita" (FREUD, 1996, p. 185). Então, existe probabilidade de que as crises vivenciadas foram sintoma da neurose do russo. Todavia, Freud não dá certeza absoluta relativa a esse ponto. Aprofundamentos envolvendo detalhes da patologia da enfermidade epiléptica não ajudariam muito, apesar de ser conveniente fazer certa distinção entre epilepsia orgânica e "epilepsia afetiva". Resumidamente falando; a pessoa portadora da primeira possui "uma moléstia no cérebro [...] sua vida mental está sujeita a uma perturbação estranha, oriunda de fora" (FREUD, 1996, p. 187). Ao passo que no segundo caso o distúrbio é expressão da própria vida mental do sujeito. Os ataques abarcam fortes crises convulsivas, aparentemente não provocadas, mudança do caráter em agressividade e irritabilidade e diminuição contínua das faculdades mentais. Acontecem mordidas de língua, momentos de incontinência urinária, e há o risco de sérios auto-danos durante as crises, que talvez venham a se reduzir, posteriormente, a curtos períodos de absence, vertigens rápidas ou são trocadas por intervalos temporais nos quais a pessoa engendra coisas que não executaria conforme seu caráter é apresentado no dia-a-dia. Mas falta generalidade a esse quadro

O cientista Helmholtz é um exemplo para que não vejamos a deterioração intelectual progressiva feita regra. A epilepsia não interferiu em sua produção de alto nível (assim como na tão elaborada criação ficcional de Dostoievski, empreendida até a proximidade de sua morte, quando contava cinqüenta enove anos). 
... essas crises, com todas suas variações, também ocorrem em outras pessoas que apresentam um desenvolvimento mental completo e, se algo mais, uma vida emocional excessiva, via de regra insuficientemente controlada. Não é de admirar que, nessas circunstâncias, tenha sido considerado impossível sustentar que a 'epilepsia' constitui uma entidade clínica isolada. A semelhança que encontramos nos sintomas manifestos parece exigir uma visão funcional deles. É como se houvesse sido disposto organicamente um mecanismo para a descarga instintual... (FREUD, 1996, p. 186).

O mecanismo não se afasta dos processos sexuais; na medicina antiga o coito era descrito enquanto uma pequena epilepsia: no ato sexual se configura uma adaptação e mitigação do método epilético de descarga. Este funcionamento, à disposição da neurose, consiste em liberar quantidades de excitação que não podem ser contidas psiquicamente. Por isso, se, fruto de alterações físicas do sistema nervoso, forma-se o quadro orgânico, não estamos impedidos de levar em conta que a mesma formatação semiológica apresente etiologia psíquica (FREUD, 1996).

Aqui, será feito determinado desvio na linha de raciocínio. Para organizar a reflexão, teceremos um pequeno esboço biográfico do romancista.

Aquele cujo lugar de artista, na opinião do fundador da psicanálise, "não se encontra muito atrás de Shakespeare" (FREUD, 1996, p. 183) nasceu a 30 de outubro de 1821, num hospital pobre de Moscou. Seu pai, Mikhail Andriéievitch Dostoievski, ali clinicava, após ter sido médico militar. Residia, com sua esposa Maria Fiódorovna Dostoievskaia e os quatro filhos (Fiódor foi o segundo mais velho), conectado ao local de serviço. Fiódor Mikhailovitch foi muito ligado à mãe, mulher terna e submissa 
que sofria com a avareza, as crises de ciúme e o autoritarismo - para com ela e as crianças - do marido, capaz, paradoxalmente, de demonstrar excessos sentimentais em algumas ocasiões. Homem instruído; procurou iniciar cedo os filhos no universo da cultura: no seio desta família crescia Dostoievski, "ao abrigo de qualquer contacto com o mundo exterior, privado de amigos, de experiência, de liberdade" (Troyat apud Nunes, 2004, p. 27). O mais provável para Freud é que as crises já se davam nesse período de infância. O lugar delas teria sido "ocupado, de início, por sintomas mais brandos e que não assumiram forma epilética até depois da experiência dilaceradora de seu décimo oitavo ano de vida: o assassinato de seu pai" (FREUD, 1996, p. 187).

Embora apareçam divergências historiográficas em torno da causa mortis de Mikhail Andriéievitch (alguns defendem que foi assassinato, executado pelos camponeses da propriedade de Darovóie, outros, um ataque apoplético (FRANK, 2003), a causa mortis em si me parece não estar em jogo; interessa o fato do falecimento e sua repercussão em Dostoievski. Este, durante a infância, experenciou a melancolia, às vezes, sendo tomado por sensação de morte. Segundo seu amigo Soloviev, dizia que ia morrer, sem apontar a causa que ao fim o levaria, e logo entrava num estado análogo à morte. Antes de adormecer, em muitos episódios, deixava notas, alertando os familiares de que poderia cair num sono bastante parecido com a condição de defunto. Dessa maneira, implorava que seu sepultamento fosse adiado por cinco dias. Tais estados significavam uma identificação com uma pessoa finada, ou que se desejasse o falecer. A pessoa em questão fora o pai: os ataques histéricos eram espécie de autopunição pelo desejo de morte, resultado de ódio, da figura paterna. Ódio que permeia o relacionamento ambivalente do menino para com o 
pai: o primeiro deseja tomar o lugar deste, querendo colocá-lo fora do caminho, a despeito de admirá-lo, e, em seu lugar, possuir a mãe. A criança percebe que empreendendo tal tentativa seria castigada com a castração. Nesse caminho, por temê-la, abdica de pôr em prática seu desejo. Este, permanecendo "inconsciente, constitui a base do sentimento de culpa" no que Freud denominou de "destino normal do chamado 'complexo de Édipo"' (FREUD, 1996, p. 189).

No entanto, devido à bissexualidade (aspecto constitucional do sujeito), o menino pode seguir na direção da feminilidade e procurar obter a posição da mãe, colocando-se no lugar de objeto amado pelo pai - o amor, assim como o ódio, sofre recalcamento. Teme-se a castração, pela punição ou custo de não ser mais querido. O temor da castração, o desejo inconsciente de morte do pai, mesmo na existência de forte apego afetivo a ele, verossimilmente desenham a etiologia da neurose do ficcionista eslavo - suas crises infantis, que consistiam em reproduzir situações análogas à morte, são passíveis de serem visualizadas na trilha de "uma identificação paterna por parte de seu ego, a qual é permitida pelo superego como punição" (FREUD, 1996, p. 190). Derivando-se do ego, o superego instaura-se separadamente e age na qualidade de representante moral, herdeiro, da influência parental; o almejo do desaparecimento do doutor Mikhail, para o infante, culminou em "sintomas precoces" de crises parecidas com a morte. E é razoável entendê-los da seguinte maneira:

para o ego, o sintoma da morte constitui uma satisfação, em fantasia, do desejo masculino e, ao mesmo tempo, uma satisfação masoquista; para o superego, trata-se de uma satisfação punitiva, isto é, uma satisfação sádica. Ambos, o ego e o superego, levam avante o papel de pai (FREUD, 1996, p. 191). 
Quando Dostoievski contava dezoito anos de idade, o já apresentado desejo foi confirmado na realidade - a epilepsia veio a comparecer ainda significando a identificação com quem ele quis perder, sendo medida autopunitiva pelo mesmo ter almejado, inconscientemente, o acontecimento. Os ataques se tornaram terríveis; e assim haveria sido o assustador acabar-se do homem que o criou $^{2}$.

$\mathrm{Na}$ Introdução Geral da Obra Completa (edição brasileira) do autor em questão, Natália Nunes (2004) molda uma conjectura muito interessante acerca do que se deu com Dostoievski frente ao óbito materno, processo que também teria se desenrolado pela conversão de fatores psíquicos para determinado quadro de abalo orgânico: ele somava, na ocasião, dezesseis anos, quando Maria Fiódorovna sucumbiu, tuberculosa e, pelo que parece, desgostosa da vida. Era vinte e sete de fevereiro de 1837, sendo que, na primavera subseqüente, o adolescente e futuro escritor apresentou uma afecção na garganta: afonia, deixando-o com vestígios - a voz velada e acentuada rouquidão - por toda a vida.

O autoritarismo do doutor Mikhail desempenhou considerável papel; atormentava a mulher com sua avareza e crises de ciúmes injustificados. O desgosto de Maria Fiódorovna, que estaria vinculado, no olhar de Nunes, às constantes turbulências no relacionamento conjugal, deixou triste impressão no rapaz Fiódor Mikhailovitch; "em criança teria assistido às cenas do despotismo paterno, teria visto por várias vezes sua terna e submissa mãe chorar" (NUNES, 2004, p. 28). Talvez ele sentisse ímpetos de acusar o pater familias visto enquanto carrasco. Este, soberanamente posicionado, exigia e extraía dos filhos obediência completa - era odiado intensa e amedrontadamente, 
mas muito amado. Como Dostoievski, submerso em tantas e tamanhas contradições afetivas, "não podia falar e gritar... a voz extinguiu-se-lhe" (NUNES, 2004, p. 28).

Essa possibilidade exposta no texto introdutório da mencionada Obra Completa afigura-se plausível. Pois, na Comunicação Preliminar dos Estudos Sobre a Histeria, o termo reação é compreendido envolvendo toda a classe de atos voluntários e involuntários - "das lágrimas aos atos de vingança - nos quais, como a experiência nos mostra, os afetos são descarregados" (BREUER \& FREUD, 1996, p. 44). A utilização cotidiana da linguagem o demonstra, por exemplo, nas expressões "desabafar pelo pranto", "desabafar através de um acesso de cólera" ou "esvair-se em cólera". Porém, o afeto fica conectado à lembrança se em alguma situação na qual o sujeito se sentiu atacado, acuado, não surgiu, de seu lado, reação "adequada" - no caso, alguma espécie de vingança, de revidação. A linguagem também reconhece, "em suas conseqüências mentais e físicas", o silêncio a respeito da ofensa sofrida: "uma mortificação", um "fazer adoecer". Desse modo, no falar estaria a ação "adequada": podendo ser um lamento ou enunciação de um segredo, uma confissão. Contudo, se não comparece reação em palavras, ações, ou, até mesmo, por via de lágrimas, a "lembrança do fato preserva sua tonalidade afetiva do início" (BREUER \& FREUD, 1996, p. 44).

Pensamos que o passado com Dostoievski, realmente, deve-se a ele não ter declarado seu ódio. Parece que houve a passagem para inervações somáticas da carga afetiva recalcada advinda de um protesto sufocado. As palavras, com todo seu conteúdo sentimental, não foram trazidas a lume. O corpo se tornou retrato não-falado, lugar de dolorosa (e, também, prazerosa) expressão simbólica do não-dito. 
E é na Comunicação Preliminar que Josef Breuer e Freud, contando dos sintomas onde puderam fazer rastreamento até atingirem seus fatores desencadeantes, colocam, no conjunto desses sintomas, nevralgias, anestesias "de naturezas muito diversas", paralisias, contraturas e, ainda, convulsões epileptoides, antes consideradas epilepsia "verdadeira" - ou de origem orgânica.

"Sim, por esse momento daria eu toda vida". Exclama o príncipe Míchkin, protagonista do clássico de Dostoievski $O$ Idiota, ao refletir quanto a um ataque. "Pensava, entre outras coisas, em que em seu estado epilético havia um grau, quase imediatamente antes do ataque", no qual, em termos de configuração sintomática: "de repente, em meio da tristeza, da bruma, da opressão espiritual [...] todas as suas dúvidas, toda a sua inquietação pareciam amansar-se de repente, sumir-se numa altíssima serenidade, repleta de júbilo..." (DOSTOIEVSKI, 2004, p. 329). Míchkin é um personagem passível de posar na galeria das criaturas dostoievskianas mais ambíguas, estranhas, místicas. É bem marcante, e, para que carregasse grande grau de realismo, foi construído a partir de experiências próprias de Dostoievski, como a da epilepsia (NUNES, 2004). Será que, nesse caso, o júbilo atribuído por Míchkin a certo momento do ataque parte, à maneira de outras passagens do livro, de sensação experimentada pelo artista russo?

No cume da crise, segundo Freud, experimenta-se um momento de extrema felicidade. Quem sabe, observando a situação de Fiódor Mikhailovitch, seja "um registro do triunfo e do sentimento de liberação experimentados ao escutar as notícias da morte, seguidos imediatamente por uma punição ainda mais cruel" (FREUD, 1996, p. 191). Na cerimônia da 
refeição totêmica, Freud imagina essa alternância de triunfo e pesar, "de alegria festiva e de luto", tomando os irmãos parricidas da horda primeva. Em Luto e Melancolia, está proposto que no momento maníaco (da psicose maníaco-depressiva) o ego supera a perda do objeto - o sujeito demonstra sua libertação de um objeto causador de sofrimento, "procurando, como um homem vorazmente faminto, novas catexias objetais" (FREUD, 1996, p. 60). O momento melancólico dá-se no comparecimento da culpa pelo desejo de desaparecimento do objeto perdido; o momento maníaco é deixado para que aporte cruel castigo. Castigo que atuou epilepticamente no corpo do mago das letras eslavas.

O fundamental escritor e crítico literário russo Vladimir Nabokov (2014), na coletânea Lições de literarura russa, e no capítulo desta dedicado ao estudo e comentário do conjunto da obra de Dostoievski, apresenta que um artista, ao iniciar uma obra, compromete-se com a busca de resolução de determinada questão artística formulada por ele próprio. Depois da seleção dos personagens, temporalidade e localidades, são determinadas as circunstâncias específicas que permitirão o natural desenvolvimento dos fatos que se almeja apresentar; daí, não deve haver violência da parte do autor para chegar ao desenlace $\mathrm{da}(\mathrm{s})$ narrativa(s) por meio das combinações e intercâmbios lógicos e espontâneos das forças postas em movimento e relação. $\mathrm{O}$ mundo que o artista engendra para tal escopo pode ser até mesmo irreal; como, "por exemplo, o mundo de Kafka ou de Gógol -, mas há uma exigência absoluta que temos o direito de fazer: esse mundo, pelo tempo que durar, deve ser plausível para o leitor ou espectador" (NABOKOV, 2014, p. 151). $O$ que tange a exigência aristotélica de verossimilhança. Nessa via, acrescenta o prosador e crítico russo: 
Assim, não é em nada essencial que Shakespeare apresente em Hamlet o fantasma do pai do personagem principal. Caso concordemos com aqueles críticos que dizem que os contemporâneos de Shakespeare acreditavam na realidade dos fantasmas, justificando desse modo que o autor os incluísse em suas peças como realidades, ou caso presumamos que tais fantasmas são meros objetos cênicos, não importa: a partir do momento que o fantasma do rei assassinado entra na peça, nós o aceitamos e não duvidamos de que Shakespeare tinha o direito de fazê-lo. Com efeito, a verdadeira medida do gênio está no fato de que o mundo por ele criado é realmente seu, não existia antes (pelo menos na literatura) e, coisa ainda mais importante, foi construído de forma plausível. Desejo considerar o mundo de Dostoiévski dessa perspectiva (NABOKOV, 2014, p. 151).

No caminho de realizar crítica a uma obra de arte, deverse-ia sempre supor que a arte constitui certo "jogo divino". E o âmbito divino, como o lúdico, é de suma importância. Ele advém mediante o elemento que o homem toca, aproximando-se de Deus, conforme se torna um verdadeiro criador por própria conta e risco. Também, trata-se de um jogo, na medida em que só continua a ser arte se nos lembrar da invenção, do aspecto ficcional dos eventos apresentados.

O crítico ainda lembra seus leitores do seguinte fato: se um artista se lança na averiguação e descrição dos matizes da alma de personagens, nosso interesse cresce em proporção à competência pela qual o artista apresenta com precisão seu caminho, tornando-se nosso guia nos meandros sombrios da psique, caso tais reações da alma ficcional sejam de uma variedade por nós perfilhada, vivenciada, 
A HISTERIA E A PERDA: CONSIDERAÇÕES SOBRE A HISTEROEPILEPSIA DE FIÓDOR M. DOSTOIEVSKI

reconhecida. Nesse aspecto, Nabokov recorta a obra de Dostoievski e traz uma lista comentada, relacionando seus personagens com "categorias de doença mental de que são acometidos" (NABOKOV, 2014, p. 153). Então, no que diz respeito a nosso trabalho, o terreno da epilepsia, vemos o crítico expor o seguinte: os quatro casos de epilepsia ao longo da obra são: Míchkin, em $O$ idiota, Smierdiákov, em Os irmãos Karamázov, Kirílov, em Os demônios e, em Humilhados e ofendidos, Nelli.

1. Míchkin é o caso clássico. Ele tem freqüentes surtos de êxtase, a tendência ao misticismo emocional, um extraordinário poder de empatia que lhe permite adivinhar os sentimentos dos outros. Exibe uma atenção meticulosa aos detalhes, em especial com respeito à caligrafia. $\mathrm{Na}$ infância, tinha convulsões frequentes e fora caracterizado pelos médicos como um irremediável "idiota".

2. Smierdiákov é o filho bastardo do velho Karamázov com uma mulher imbecil. Quando criança, Smierdiákov demonstrou grande crueldade, gostando de enforcar gatos e enterrá-los em cerimônias profanas. $\mathrm{Na}$ juventude, desenvolveu um senso exagerado de autoestima, beirando às vezes a magalomania, tinha convulsões freqüentes etc. (NABOKOV, 2014, p. 153).

No romance Os demônios, Kirílov é o bode expiatório. Epilético incipiente; digno, gentil, consciencioso - e de personalidade epileptoide. No sentido de Míchkin, às vezes descreve de forma premonitória o ataque, destacando impressões ou sintomas. Seu caso é "complicado" (palavra de Nabokov), pela tendência suicida. Já o vaso de Nelli não é relevante e não acrescenta algo aos outros três no que diz respeito à sintomática epileptoide. Assim, o que almejamos 
observar sobre a crítica de Nabokov, é que ele separa esses casos dos de demais personagens que apresentariam histeria ao invés de epilepsia. Porém, não é o caso da proposta de nosso trabalho, como já exposto; trata-se de discutir-se a histeroepilepsia na biografia e na feitura de personagens na obra de Dostoievski, ao passo em que é plausível encontrar coincidências e comparações frutíferas para o entendimento da mencionada enfermidade conforme ela se mostra, desvelase, entre a vida e a obra desse grande escritor, para que ela possa ser melhor entendida em termos clínicos, de observação diagnóstica, por exemplo, tendo em conta sua configuração sintomática e etiológica e, ao mesmo tempo, em termos estéticos: personagens formados de modo a trazer a carga sintomática de seu autor, no que este possa trazer de percepção consciente e projeção inconsciente de sua constelação anímica - que fala, expressa-se, mediante seus sinyomas físicoemocionais e as veredas artísticas que se imiscuem entre conteúdo, forma estilística e formação de caracteres ao longo de sua obra labiríntica; polifônica entre conteúdos, gêneros de escrita e, até mesmo, polifonia de vozes sociais, como destaca e articula o estudo de Mikhail Bakhtin - sobre o qual, em todo caso, não nos cabe neste trabalho fazer exposição conceitual.

Lembrando, então, do período siberiano, no qual Dostoievski esteve detido quatro anos na prisão e serviu, ulteriormente, durante cinco anos, como soldado raso devido a seu envolvimento num grupo revolucionário que pretendia derrubar o czar Nicolau I: se fosse provado que ele se libertou, nesses anos, das crises, "isso simplesmente daria substância à opinião de que elas eram sua punição" (FREUD, 1996, p. 191). Poder-se-ia, com mais elevado grau de segurança, colocar que a punição histeroepilética foi substituída pela punição judicial. 


\section{NOTAS}

${ }^{1}$ Psicanalista, doutorando em psicanálise e tradução pela UFSC, mestre em Estudos Literários pela UFG, especialista em Filosofia Política e graduado em Psicologia pela PUC-GO. Exerce, em Goiânia, a clínica psicanalítica, em consultório particular.

${ }^{2}$ É possível que o doutor Mikhail tenha sido brutalmente assassinado pelos mujiques de sua propriedade. 


\section{REFERÊNCIAS}

BREUER \& FREUD. Comunicação Preliminar: Estudos Sobre a Histeria. In: Edição Standard das Obras Completas de Sigmund Freud, Vol. II. Rio de Janeiro, 1996, Imago.

FRANK, J. Dostoievski: as Sementes da Revolta - 1821 a 1849. São Paulo, 2003, Edusp.

FREUD, S. Luto e Melancolia. In: Edição Standard das Obras Completas de Sigmund Freud. Vol. XIV, pp. 249-263. Rio de Janeiro, 1996, Imago.

FREUD, S. Dostoievski e o Parricídio. In: Edição Standard das Obras Completas de Sigmund Freud, Vol. XXI, pp. 183-198. Rio de Janeiro, 1996, Imago.

NABOKOV, V. Fiódor Dostoiévski. In: Lições de literatura russa. São Paulo, Três Letras, 2014.

NUNES, N. Introdução Geral. In: Fiódor M. Dostoievski: Obra Completa. Vol. I, pp. 24-122. Rio de Janeiro, 2004, Nova Aguilar.

NUNES, N. Nota Preliminar. In: Fiódor M. Dostoievski: Obra Completa. Vol. III, pp. 131-132. Rio de Janeiro, 2004, Nova Aguilar.

STRACHEY, J. Nota do Editor Inglês. In: Edição Standard das Obras Completas de Sigmund Freud, Vol. XXI, pp. 181-182. Rio de Janeiro, 1996, Imago. 